\title{
Effects of Diode and Nd:YAG Laser Irradiation on Friction Forces Between Two Types of Ceramic Brackets and Rhodium-Coated Archwires
}

\author{
Hannaneh Ghadirian $^{1}$, Allahyar Geramy ${ }^{\circledR}$, Mohammad Ali Keshvad $^{*^{\circledR}}$, Soolmaz Heidari ${ }^{\circledR}$, Nasim $^{\circledR}$ \\ Chiniforush $^{4,5}$ (D)
}

${ }^{1}$ Assistant Professor of Orthodontics, Department of Orthodontics, Tehran University of Medical Sciences, Tehran, Iran ${ }^{2}$ Professor of Orthodontics, Department of Orthodontics, Tehran University of Medical Sciences, Tehran, Iran ${ }^{3}$ Assistant Professor, Department of Operative Dentistry, Dental Caries Prevention Research Center, Qazvin University of Medical Sciences, Qazvin, Iran

${ }^{4}$ Assistant Professor, Dental Implant Research Center, Dentistry Research Institute, Tehran University of Medical Sciences, Tehran, Iran

${ }^{5}$ Department of Surgical Sciences and Integrated Diagnostics, University of Genoa, Italy

\section{*Correspondence to}

Mohammad Ali Keshvad,

Orthodontic Department, School of Dentistry, Tehran University of Medical Sciences, North Kargar Street, Tehran, Iran Tel: +989128026404;

Email: M Ali_Keshvad@yahoo. com

Published online March 14 2021

\begin{abstract}
Introduction: Ceramic brackets have gained increasing popularity among dental clinicians and orthodontic patients but friction is a major concern when using them. This study sought to assess the effects of diode and Nd:YAG (neodymium-doped yttrium aluminum garnet) laser irradiation on friction forces between two types of ceramic brackets and rhodium-coated esthetic archwires.

Methods: Thirty polycrystalline and 30 poly-sapphire brackets were divided into 6 groups $(n=10)$ as follows: (I) control polycrystalline brackets (no laser irradiation), (II) polycrystalline brackets subjected to diode laser irradiation, (III) polycrystalline brackets subjected to $\mathrm{Nd}$ :YAG laser irradiation, (IV) control poly-sapphire brackets (no laser irradiation), (V) poly-sapphire brackets subjected to diode laser irradiation, and ( $\mathrm{VI}$ ) poly-sapphire brackets subjected to $\mathrm{Nd}$ :YAG laser irradiation. The bracket slots were laser-irradiated on a custom-made table. Sixty 5-cm pieces of rhodium-coated archwires were used for the friction test in a universal testing machine at a speed of $10 \mathrm{~mm} / \mathrm{min}$. Ten brackets from the six groups underwent scanning electron microscopy (SEM), X-ray diffraction (XRD) and energy-dispersive X-ray spectroscopy (EDX).

Results: The frictional resistance value of polycrystalline brackets was significantly higher than that of poly-sapphire brackets, irrespective of laser type $(P<0.05)$. Irradiation of diode and Nd:YAG lasers, compared with the control group, had no significant effect on friction, irrespective of bracket type $(P>0.05)$.

Conclusion: It appears that diode and $\mathrm{Nd}$ :YAG laser irradiation cannot significantly decrease the friction. Future studies are warranted on different laser types with variable exposure.

Keywords: Orthodontic Friction, Laser Therapy, Esthetics, Orthodontic Bracket, Ceramics
\end{abstract}

\section{Introduction}

Adults demanding orthodontic treatment without the metallic appearance of orthodontic brackets and wires currently comprise a large portion of orthodontic patients. Thus, orthodontists are obliged to meet the esthetic demands of their patients. Lingual orthodontics, clear aligners, ceramic brackets, and tooth-colored orthodontic archwires are the most recent modalities suggested to meet the esthetic demands of orthodontic patients. ${ }^{1}$ Among the available modalities, ceramic brackets have gained more popularity due to their greater similarity to the conventional orthodontic systems and lower need for modification of treatment mechanics while being esthetically acceptable and easily available. ${ }^{2}$

However, aside from some drawbacks of ceramic brackets such as enamel wear, fragility, and difficult bonding, their high friction coefficient and its adverse effect on the treatment course are a major concern for dental clinicians. The friction of ceramic brackets is so high that can cause up to $60 \%$ of force loss. ${ }^{3}$ Several studies have evaluated the efficacy of different combinations of archwires and brackets, and have reviewed their properties such as surface roughness and friction, their effect on the duration of treatment, and their cost-effectiveness. ${ }^{4,5}$

Please cite this article as follows: Ghadirian H, Geramy A, Keshvad MA, Heidari S, Chiniforush N. Effects of diode and nd:yag laser irradiation on friction forces between two types of ceramic brackets and rhodium-coated archwires. J Lasers Med Sci. 2021;12:e13. doi:10.34172/jlms.2021.13. 
For instance, Cacciafesta et $\mathrm{al}^{6}$ reported that ceramic brackets with metal slots had significantly lower friction than ceramic brackets without metal slots. However, their friction was still higher than that of metal brackets. They concluded that ceramic brackets with metal slots are excellent alternatives to meet both the esthetic and mechanical requirements.

Surface modification has been commonly used in studies on friction or bond strength to reach the desired outcome. ${ }^{7}$ For instance, zinc oxide nanoparticle coating has been suggested to decrease the friction between ceramic brackets and orthodontic wires. ${ }^{8}$ The application of lubricants is another suggested strategy to decrease the frictional forces. ${ }^{9}$ Laser treatment is another emerging, fast-growing modality in dental sciences. Laser irradiation results in energy concentration close to the surface of opaque targets and leads to physicochemical reactions on the surface, which would morphologically alter the ceramic surface. Melting, reorientation of crystals, microexplosions, and formation of bubble-shaped blisters are among the surface modifications caused by laser irradiation, which may vary depending on the target tissue, laser energy, duration of laser irradiation, and laser wavelength. ${ }^{10}$

Evidence shows that irradiation of high-power $\mathrm{CO}_{2}$ and excimer lasers for the purpose of glazing results in the smoothness of the surface, without modifying the inherent properties of alumina ceramics (ceramic bracket material). ${ }^{11}$ Also, atomic force microscopic observations have shown that the Nd:YAG (neodymium-doped yttrium aluminum garnet) laser provides a smoother ceramic surface compared with acid-etching and air abrasion. The same findings have been reported for the Er:YAG laser, and it has been emphasized that laser irradiation creates significantly lower irregularity than other surface modifications. ${ }^{12,13}$

A systematic review on the effect of laser irradiation on ceramic surface properties discussed that the absorption of Nd:YAG laser by the ceramic structure depends on the water content, surface roughness, and pigmentation of ceramic. Following absorption, laser energy is converted to heat and leads to ceramic surface melting, its re-solidification, volumetric changes, and subsequent morphological modifications in the ceramic surface. ${ }^{14}$ Unlike the Er:YAG laser, the diode laser cannot pass through the ceramic and is absorbed by the surface. ${ }^{15}$

Considering all the above, the purpose of this study was to assess the effects of Nd:YAG and diode laser irradiation, as two commonly used lasers in dentistry, on the friction forces between two types of ceramic brackets and rhodium-coated esthetic archwires.

\section{Materials and Methods Sample Preparation}

A total of 35 edgewise polycrystalline alumina ceramic brackets with $0.022 \times 0.028$-inch slots and 35 edgewise poly-sapphire alumina ceramic brackets with $0.022 \times$ 0.028 -inch slots were used in this study. Three brackets of each type were used for scanning electron microscopy (SEM). Also, two brackets of each type underwent $\mathrm{X}$-ray diffraction (XRD) and energy-dispersive X-ray spectroscopy (EDS) for more detailed assessment of ceramic structure and the remaining were used for the friction test.

A total of 30 prefabricated $0.019 \times 0.025$-inch rectangular rhodium-coated stainless steel archwires were also used. The $5-\mathrm{cm}$ end segments of archwires at both ends were used for the friction test. Table 1 lists the items used in this study.

This experimental study had six groups as follows:

- Group I: Ten polycrystalline brackets without laser irradiation (control group 1)

- Group II: Ten polycrystalline brackets subjected to diode laser irradiation

- Group III: Ten polycrystalline brackets subjected to Nd:YAG laser irradiation

- Group IV: Ten poly-sapphire brackets without laser irradiation (control group 2)

- Group V: Ten poly-sapphire brackets subjected to diode laser irradiation

- Group VI: Ten poly-sapphire brackets subjected to Nd:YAG laser irradiation

The archwires and bracket slots were first cleaned with gauze dipped in ethanol to eliminate any residual oil remaining from the manufacturing process. The brackets then underwent laser irradiation. Table 2 presents the characteristics of diode and Nd:YAG lasers used in this study. The tip diameter was $320 \mu \mathrm{m}$ for both laser handpieces.

The brackets in groups II, III, V and VI were

Table 1. Items Used in This Study

\begin{tabular}{|c|c|c|c|}
\hline Items & Number & Manufacturing Company & Characteristics \\
\hline Polycrystalline brackets & 35 & $\begin{array}{l}\text { Ceramic Dental Brackets, CDB corporation, } \\
\text { Wilmington, North Carolina, USA. }\end{array}$ & $\begin{array}{l}\text { Straight-wire edgewise, ceramic bracket 7D-1 } \\
\text { series. }\end{array}$ \\
\hline Poly-sapphire brackets & 35 & $\begin{array}{l}\text { Ceramic dental brackets, CDB corporation, } \\
\text { Wilmington, North Carolina, USA. }\end{array}$ & $\begin{array}{l}\text { Straight-wire edgewise, ceramic bracket 9S-1 } \\
\text { series }\end{array}$ \\
\hline $\begin{array}{l}0.019 \times 0.025 \text {-inch esthetic } \\
\text { archwires }\end{array}$ & 30 & Sentalloy, GC Orthodontics, Japan. & Rhodium coated stainless steel archwires \\
\hline Elastic O-ring & 60 & $\begin{array}{l}\text { Dentaurum intraoral elastics, Dentarum } \mathrm{GmbH} \& \\
\text { Co. KG, Ispringen, Germany. }\end{array}$ & Elastomer (polymer) \\
\hline
\end{tabular}


Table 2. Characteristics of Diode and Nd:YAG Lasers Used in This Study

\begin{tabular}{lcc}
\hline Type of Laser Diode & Diode 980 nm & Nd:YAG 1064 nm \\
\hline Model & $\begin{array}{c}\text { Simpler, Doctor } \\
\text { Smile, Italy }\end{array}$ & $\begin{array}{c}\text { LightWalker, Fotona, } \\
\text { Slovenia }\end{array}$ \\
Emission mode & $\mathrm{CW}$ & Pulsed \\
Time on/time off & $\mathrm{CW}$ & $650 \mu \mathrm{s}$ \\
Delivery system & Fiber optic & Fiber optic \\
Energy distribution & Gaussian & Gaussian \\
Peak power & $1 \mathrm{~W}$ & $230.76 \mathrm{~W}$ \\
Average power & $1 \mathrm{~W}$ & $1.5 \mathrm{~W}$ \\
Spot diameter at the focus & $320 \mu \mathrm{m}$ & $320 \mu \mathrm{m}$ \\
Focus-to-tissue & Yes & Yes \\
Spot area at the tissue & $320 \mu$ & $320 \mu$ \\
Average power density at & $1244 \mathrm{~W} / \mathrm{cm}^{2}$ & $1866 \mathrm{~W} / \mathrm{cm}^{2}$ \\
the tissue & $\mathrm{No}$ & $\mathrm{No}$ \\
Water irrigation & $\mathrm{No}$ & $\mathrm{No}$ \\
Air and aspirating airflow & &
\end{tabular}

individually fixed at the center of a mobile custom-made table (Figure 1) with sticky wax. The laser handpiece was fixed to the designed vertical clamp while its tip had a distance of $1 \mathrm{~mm}$ from the slot (Figure 2). After ensuring the correct positioning of the bracket and laser handpiece, the table started to move and the operator commenced laser irradiation. The bracket slot was subjected to laser irradiation while moving for a total duration of 15 seconds. During the procedure, another operator carefully monitored the path of movement of the bracket to ensure that it did not deviate from the laser irradiation path.

\section{Friction Test}

After laser irradiation, the samples underwent the friction test in a universal testing machine (Z50; ZwickRoell, Ulm, Germany). A fixture, custom designed for this purpose, was used to hold the wire along the direction of load application to the bracket. In this design, a pure load was applied to the bracket along the direction of the wire. The instrument used to pull the bracket had a rigid structure (Figure 3). The applied load caused sliding of the bracket attached to the elastomeric $\mathrm{O}$-ring along the wire. The load cell was calibrated between $0-5 \mathrm{~N}$, and the brackets were dragged over the wire at a speed of $10 \mathrm{~mm} / \mathrm{min}$ in a $5-\mathrm{mm}$ path. ${ }^{16}$ Static friction was measured as the maximum load required to initiate the bracket movement along the wire. The frictional resistance value was calculated by dividing the measured static force by the cross-sectional area of the bracket using the following equation ${ }^{17}$ :

frictional force

12.83

Scanning Electron Microscopy/Energy-Dispersive X-Ray SEM/EDS

SEM/EDS (VEGA, TESCAN, Czech republic/Rontec,
Germany) with $15 \mathrm{kV}$ accelerated voltage was performed to assess the morphology and composition of ceramics used in the bracket structure. In order to decrease the charge, the samples were gold-coated with a thin layer of gold.

\section{$X$-Ray Diffraction}

XRD (X'Pert PRO MPD, PANalytical, the Netherlands) with a copper target was performed at $40 \mathrm{kV}, 40 \mathrm{~mA}, 0.02$ step size, and $5-120^{\circ} 2 \theta$ to identify the crystalline phases in the composition of brackets. The crystalline phases of ceramic brackets were identified and quantified according to the method described by Krimm and Tobolsky. ${ }^{18}$ In this method, the percentage of crystallinity $\left(\mathrm{I}_{c}\right)$ is calculated by the surface ratio of crystal $\left(A_{c}\right)$ in the diffractogram of the ceramic sample to the total surface $\left(A_{t}=\right.$ amorphous + crystalline) in the diffractogram using the equation below:

$I_{C}=\left(A_{c} / A_{t}\right) \times 100 \%$

\section{Statistical Analysis}

Two-way ANOVA was applied to compare the friction and assess the effect of bracket type and laser type on friction with the wire. All statistical analyses were carried out using SPSS version 22 (SPSS Inc., IL, USA) at a 0.05

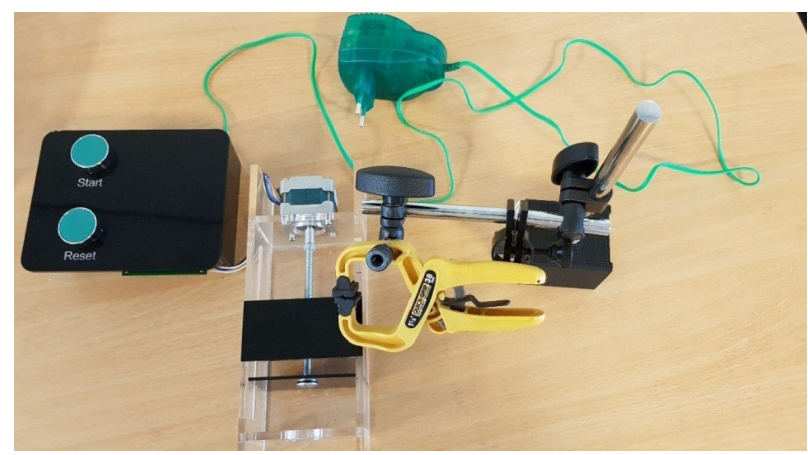

Figure 1. Custom-designed table for movement of bracket during laser irradiation

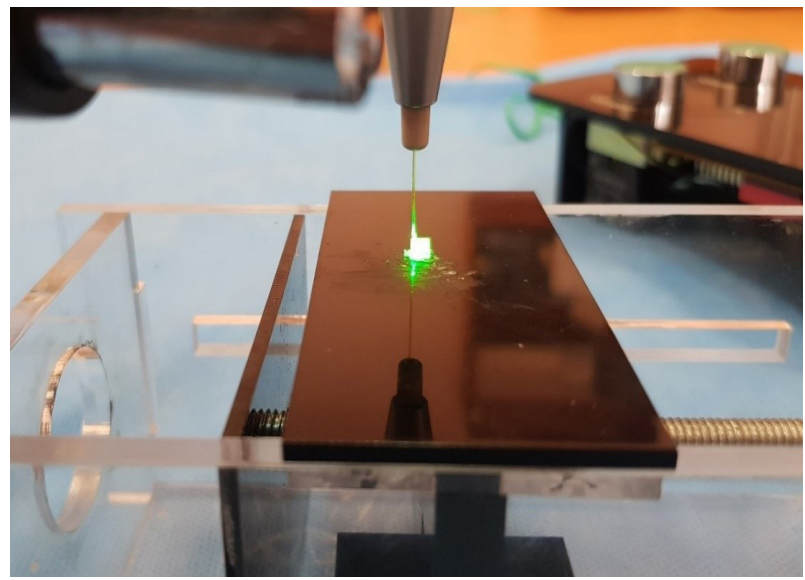

Figure 2. Laser irradiation of bracket slot 


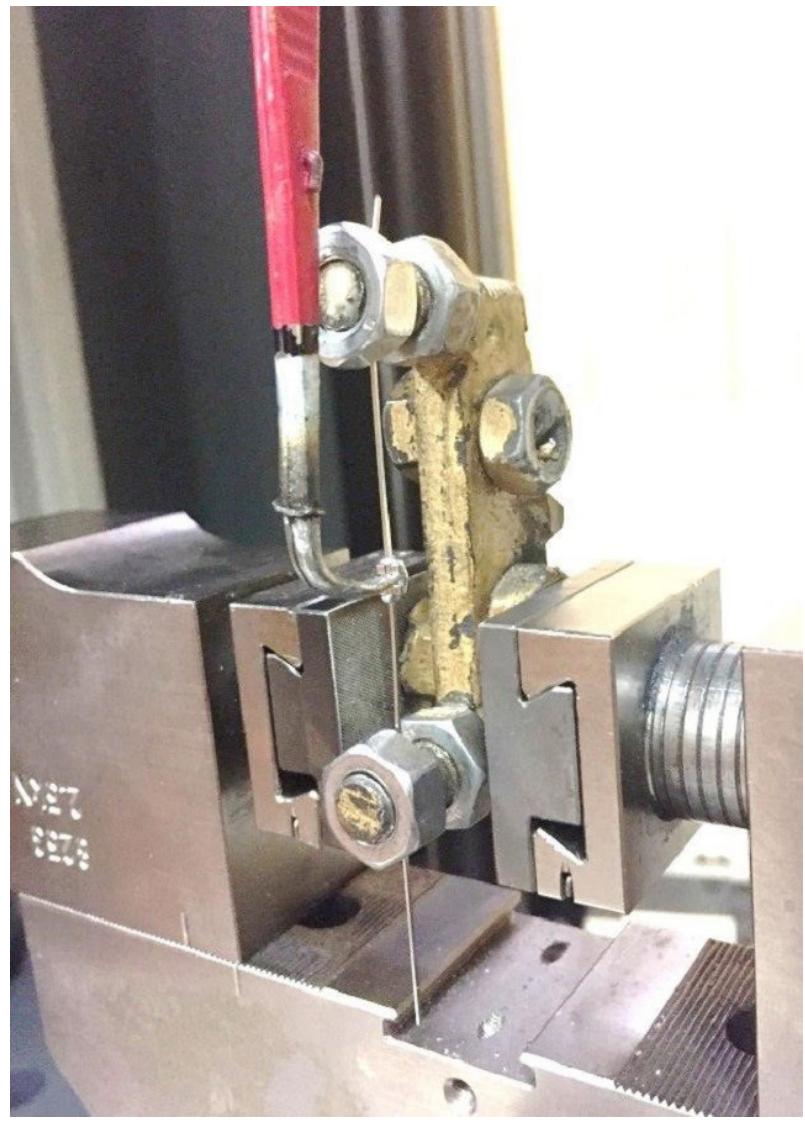

Figure 3. Fixing the wire and bracket to the designed fixture

level of significance.

\section{Results}

\section{Friction Test}

Table 3 presents the mean frictional resistance value during the bracket movement along the archwire in the six groups.

Evaluation of the effect of bracket type and laser type on the frictional resistance value revealed that the interaction effect of bracket type and laser type on the frictional resistance value was not significant $(P=0.406)$. Comparison of the mean frictional resistance value of the two bracket types revealed that polycrystalline brackets in all three groups of control, diode laser, and Nd:YAG laser had significantly higher frictional resistance value than poly-sapphire brackets $(P<0.001)$.

Comparison of the mean frictional resistance value between the two laser types revealed no significant difference in the same bracket groups of diode laser, Nd:YAG laser and control, which indicates that laser type had no role in increasing or decreasing the friction of ceramic brackets with the wire $(P=0.427)$.

\section{SEM/EDS Findings}

The polycrystalline brackets had rougher surfaces than the poly-sapphire brackets and showed irregularly arranged
Table 3. Mean frictional resistance value $\left(\mathrm{N} / \mathrm{mm}^{2}\right)$ during the bracket movement along the archwire in the six groups $(n=10)$

\begin{tabular}{llllll}
\hline Bracket Type & $\begin{array}{l}\text { Laser } \\
\text { Type }\end{array}$ & Minimum & Maximum & Mean & $\begin{array}{l}\text { Standard } \\
\text { Deviation }\end{array}$ \\
\hline \multirow{2}{*}{ Polycrystalline } & Control & 0.13 & 0.27 & 0.1850 & 0.04515 \\
& Diode & 0.16 & 0.33 & 0.2027 & 0.04734 \\
& Nd:YAG & 0.14 & 0.28 & 0.1927 & 0.04671 \\
& Control & 0.09 & 0.19 & 0.1292 & 0.03223 \\
Poly-sapphire & Diode & 0.10 & 0.15 & 0.1249 & 0.01817 \\
& Nd:YAG & 0.07 & 0.14 & 0.1060 & 0.01940 \\
\hline
\end{tabular}

grains on their surface. Also, some particles were noted on their surface that had caused surface irregularities.

The poly-sapphire brackets had distinct, regular grains with clear grain boundaries, creating a uniform surface. Also, the grain size in these brackets was larger than that in polycrystalline brackets, and the grain boundaries were clearer. Laser irradiation of polycrystalline brackets did not cause significant surface modification except for slight rounding of the borders of some grains (mainly by the diode laser). Nonetheless, the diode laser had a more prominent effect on poly-sapphire brackets, and some melting points were observed. Nd:YAG laser irradiation did not have a significant effect on poly-sapphire brackets (Figures 4 and 5).

\section{X-Ray Diffraction Test Results}

According to the XRD test results, $\mathrm{Al}_{2} \mathrm{O}_{3}$ was the main crystalline phase in the composition of both brackets, and the intensity of the peaks of this phase was higher in the conventional polycrystalline ceramic. The percentage of crystallinity was found to be $42.20 \%$ in the polycrystalline and $26.13 \%$ in the poly-sapphire brackets (Figure 6).

\section{Discussion}

Although a combination of ceramic brackets and esthetic archwires can achieve patient and orthodontist satisfaction by creating an exceptional, almost invisible appearance, high friction forces can have adverse consequences such as the application of loads exceeding the biological tolerance threshold of the teeth and loss of posterior anchorage in contemporary orthodontic systems with mainly sliding mechanics. ${ }^{19}$ Thus, it is clinically important to assess the friction of different types of ceramic brackets to come up with strategies to decrease it. Aside from the factors such as the method of ligation, the contact angle of bracket and wire, and orthodontic treatment phase, the bracket-wire contact area is another important parameter involved in friction. Some strategies have been proposed to modify the contact area of bracket and wire and subsequently decrease friction. For instance, Tanne et $\mathrm{al}^{20}$ discussed that friction can be minimized by changing the manufacturing process of ceramic brackets and creating a smoother surface. Thus, in this study, the ceramic bracket slots were irradiated with diode and Nd:YAG lasers to modify their 

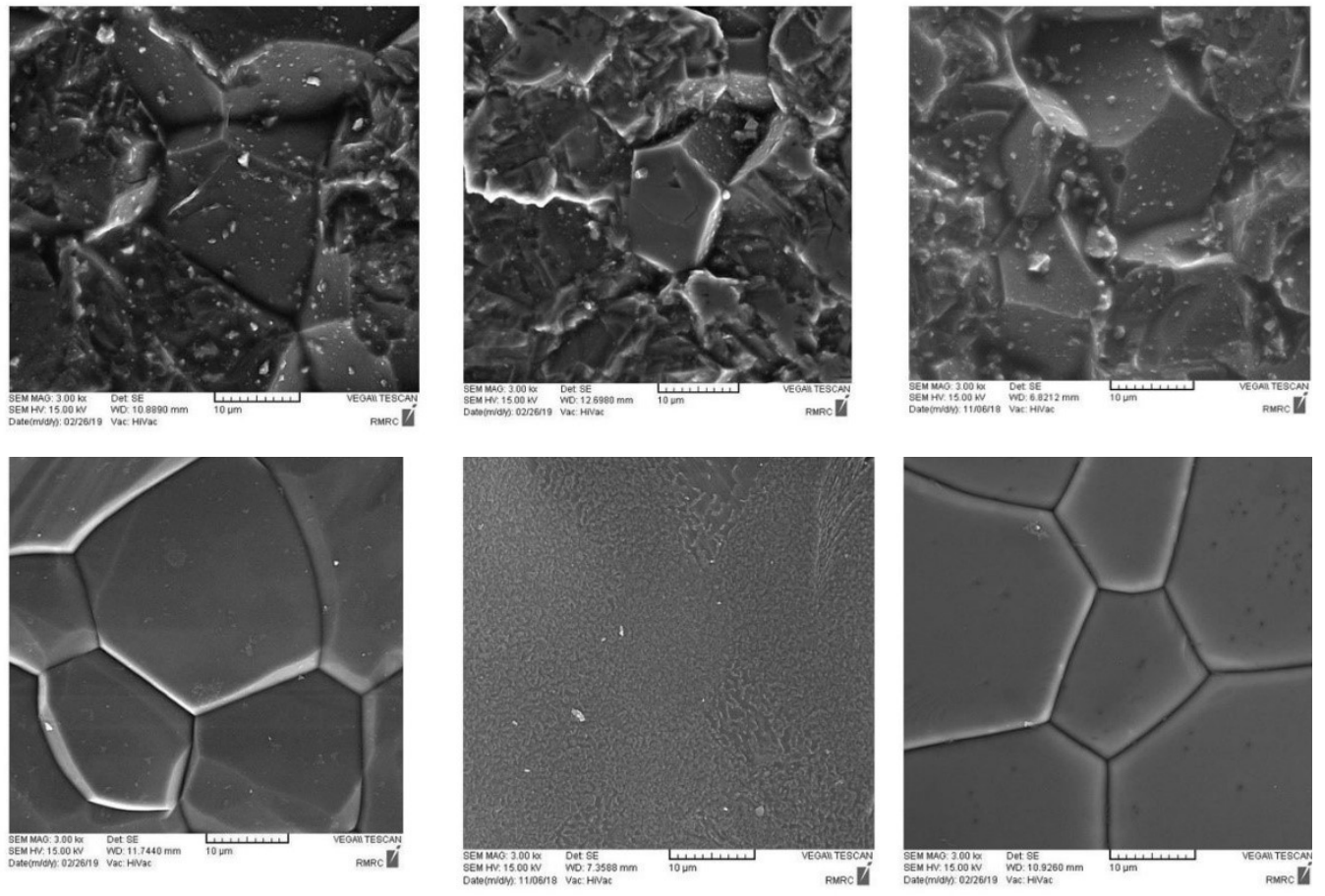

Figure 4. SEM micrographs of (a) polycrystalline bracket without laser irradiation, (b) polycrystalline bracket subjected to diode laser irradiation, (c) polycrystalline bracket subjected to Nd:YAG laser irradiation, (d) poly-sapphire bracket without laser irradiation, (e) polysapphire bracket subjected to diode laser irradiation, (f) poly-sapphire bracket subjected to Nd:YAG laser irradiation

surface in contact with the wire and assess the effect of laser irradiation on friction.

Two types of ceramic brackets were tested in this study, including a conventional polycrystalline type with an opaque appearance and a poly-sapphire type with a translucent appearance. The difference in the appearance of the two types of ceramic brackets can be explained based on SEM micrographs. The SEM micrographs of the conventional polycrystalline brackets indicated an irregular structure and variable grain sizes without distinct boundaries, which seem to play a major role in the refraction of light and consequently the opaque appearance of the brackets. However, the SEM micrographs of the poly-sapphire brackets indicated more regular orientation of crystals with distinct boundaries and relatively uniform sizes. Such different structures and crystallinity phases were also noted in XRD analysis such that the polycrystalline brackets showed a higher crystalline phase with more intense $\mathrm{Al}_{2} \mathrm{O}_{3}$ peaks and a lower glass phase (amorphous). These findings supported the results of EDX analysis. The aluminum content was found to be higher than other elements, and the ceramic composition of the two bracket types was the same. Despite similar composition, different crystalline structures and the percentage of crystallization may explain the differences between the two ceramic brackets. The crystalline phase leads to greater light scattering and opacity. ${ }^{21}$ The difference in the crystalline structure of the two brackets not only affects their appearance, but also influences the results of the friction test. In the control group of the conventional polycrystalline brackets $(n=10)$, the mean frictional resistance value was measured by the universal testing machine to be $0.18 \mathrm{~N} / \mathrm{mm}^{2}$; this value was $0.12 \mathrm{~N} / \mathrm{mm}^{2}$ in the control group of the poly-sapphire brackets, which indicated significantly higher friction of brackets with an irregular crystalline structure. Such a significant difference was noted not only in the control group, but also in all laser-irradiated groups between the two bracket types. Arash et $\mathrm{al}^{22}$ showed that the friction of polycrystalline brackets was significantly higher than that of monocrystalline brackets. Assessment of the effect of the diode laser on the friction of brackets with wire revealed that diode laser irradiation of polycrystalline and poly-sapphire brackets could not significantly change their friction compared with the control groups $(P>0.05)$. The mean frictional resistance value of polycrystalline brackets was $0.20 \mathrm{~N} / \mathrm{mm}^{2}$ while this value was $0.12 \mathrm{~N} / \mathrm{mm}^{2}$ for poly-sapphire brackets. This finding indicates that the diode laser with the adopted settings in this study could not cause significant surface modification although it caused morphological changes in the poly-sapphire brackets. These findings confirmed the results of Stubinger et al, to some extent, regarding the effect of irradiation of different laser types on zirconia implants. They concluded that the diode laser, unlike the $\mathrm{Nd}$ :YAG and $\mathrm{CO}_{2}$ lasers, could not alter the ceramic surface morphology. Unlike the Er:YAG laser, the diode laser did not pass through the ceramic and was absorbed by the ceramic surface. ${ }^{15}$ Assessment 


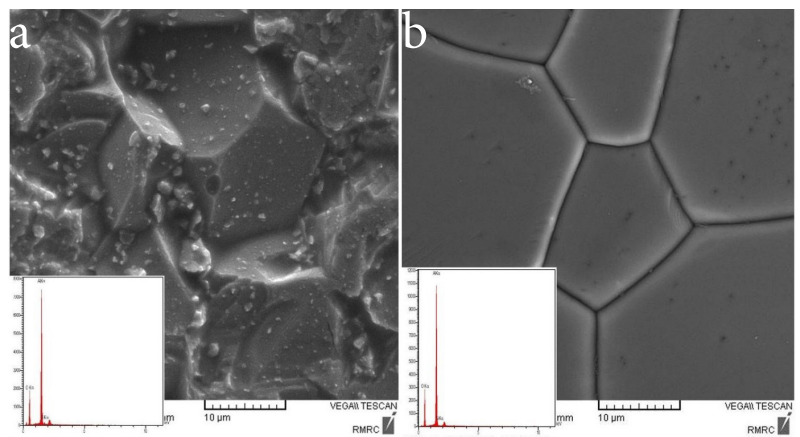

Figure 5. Results of EDS analysis for (a) polycrystalline bracket and (b) poly-sapphire bracket

of SEM micrographs following diode laser irradiation revealed that the irregular surface of polycrystalline brackets did not change significantly; the most prominent modification was rounding of the corners of the grains, and the surface irregularity was similar to that of the control group. The SEM micrographs of the poly-sapphire brackets after diode laser irradiation revealed evidence of melting and destruction of grain boundaries although these alterations did not contribute to a significant change. Such modifications indicate energy absorption by poly-sapphire brackets and have been the focus of some previous investigations. Feldon et $\mathrm{al}^{23}$ reported that the diode laser greatly passes through the structure of translucent monocrystalline brackets while most of the laser energy is absorbed by the bracket following an increase in the percentage of crystals and further opacity of the bracket; however, they did not provide photographs of laser-irradiated brackets. Ivanov ${ }^{24}$ measured the pulpal temperature following diode laser irradiation of monocrystalline and polycrystalline brackets. They noticed lower pulpal temperature in the polycrystalline group while the use of monocrystalline brackets resulted in higher pulpal temperature since they allowed greater passage of laser energy. The authors declared that the polycrystalline bracket structure probably allows greater energy absorption; however, they did not provide images of the brackets.

It should be noted that friction has a direct correlation with the compression load of surfaces over each other, the nature of surfaces, chemical reactions, use of lubricants, and so on. As stated by Kusy and Whitley, ${ }^{25}$ the required load for shearing of microscopic points of attachments between the two surfaces as well as the resistance created by surface irregularities are among the determinants of the friction value. In other words, the friction coefficient is more influenced by the yield strength and shear strength of attachment points rather than the surface roughness. Therefore, a material with high surface roughness does not necessarily have a high friction coefficient. ${ }^{25}$ They also evaluated the composition of different wires and brackets and observed that the
XRD

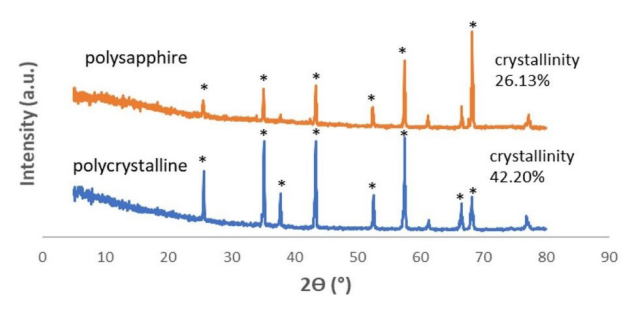

$*=\mathrm{Al}_{2} \mathrm{O}_{3}$ (Corundum)

Figure 6. XRD analysis for phase identification of the two bracket types

friction coefficient of polycrystalline ceramic brackets and steel and beta-titanium wires was significantly higher than the combination of bracket and steel wires, while the nickel titanium wires had the highest surface roughness (they performed laser specular reflectance measurements for the assessment of roughness). ${ }^{26}$

Nd:YAG laser irradiation could not cause a significant change in friction compared with the control group $(P>0.05)$, neither in the polycrystalline nor in the polysapphire brackets $\left(0.10 \mathrm{~N} / \mathrm{mm}^{2}\right.$ for the poly-sapphire and $0.19 \mathrm{~N} / \mathrm{mm}^{2}$ for the polycrystalline brackets). The effect of the Nd:YAG laser on bracket morphology was much lower than that of the diode laser according to SEM micrographs. Nonetheless, Harimkar and Dahotre ${ }^{27}$ evaluated the effect of Nd:YAG laser irradiation on the surface properties of alumina ceramics and reported that according to the XRD and SEM analyses, the resultant surface properties and thermal alterations dictate the changes in the size and shape of the grains and the ceramic phases and consequently affect the surface-related behaviors such as friction. They showed that higher laser energy results in the melting of a higher percentage of aluminum oxide crystals although laser parameters in their study were different from ours. Lee et $\mathrm{al}^{28}$ discussed that dynamic melting of the ceramic surface and its re-solidification decreased the surface porosity and roughness and resulted in the formation of a mainly amorphous, glassy superficial layer. Similar to our methodology, they employed SEM/ EDS for bracket surface analysis. ${ }^{27,28}$ It should be noted that the mean friction of brackets did not significantly change following irradiation of the two laser types, which indicates no superiority of any laser type over the other.

In a study highly similar to our study, Rabiee et $\mathrm{al}^{29}$ evaluated the effect of $\mathrm{CO}_{2}$ laser irradiation on the friction between steel wire and polycrystalline bracket. The type of laser and use of different $\mathrm{CO}_{2}$ laser powers in their study were different from our methodology. They found that increasing the $\mathrm{CO}_{2}$ laser power significantly affected the friction, and lower friction was noted in groups subjected to laser irradiation with energy level $>70 \mathrm{~J} / \mathrm{cm}^{2}$. They also added that atomic force microscopic 
images revealed more homogenous formation of laser blisters in higher laser powers, while lower powers of laser yielded a more irregular surface. Quantitative assessment of surface roughness in their study revealed lower ceramic surface roughness following the use of higher laser powers; nonetheless, the lowest surface roughness was reported in the control group (no laser irradiation). They only evaluated one type of bracket. In explaining the mechanism of friction reduction by the formation of laser blisters, they discussed that laser blisters increase the homogeneity and uniformity of the porous surface and consequently decrease the contact area of bracket and wire. Thus, sliding of wire over these blisters would result in a smaller contact area and subsequently lower friction. The uniformity of laser blisters increased by an increase in laser power.

Arash et $\mathrm{al}^{30}$ evaluated the effect of Er:YAG laser irradiation of polycrystalline brackets and stated that at a $0^{\circ}$ angle between the wire and bracket (as in our study), increasing the laser power from 100 to $300 \mathrm{~mJ} / \mathrm{s}$ significantly decreased the friction; however, at a $10^{\circ}$ angle between the wire and bracket, the change in friction was no longer significant. This finding highlights the fundamental role of binding in the generation of resistance against sliding of the teeth. Irrespective of laser type in their study, which was different from the lasers used in our study, their findings highlighted the significance of using different laser powers. They attributed the reduction in friction to the melting of superficial grains and rounding of their corners. The same observations were reported by Abdallah et $\mathrm{al}^{11}$ following high-power $\mathrm{CO}_{2}$ laser irradiation of In-Ceram ceramic surfaces, such that laser-irradiated ceramics showed smoother surfaces. However, in our observations of SEM micrographs, the grains did not experience a significant change in size after laser irradiation.

Future studies are required to use different laser types with different powers, durations and wavelengths to obtain more reliable results. Also, the clinical setting must be simulated as much as possible. The use of artificial saliva and taking into account the role of masticatory forces and bacterial plaque can greatly enhance the generalizability of in vitro results to the clinical setting.

Moreover, optical profilometry and atomic force microscopy can be employed in future studies to quantitatively assess the surface modification of slots. Furthermore, the use of different laser settings can further shed light on the results. Last but not least, the conventional steel wires can be used as the control group for the purpose of comparison in future studies on the effect of coating of esthetic wires on friction.

\section{Conclusion}

Irradiation of the diode laser, compared with the Nd:YAG laser, with the suggested settings (in terms of power and duration) caused significant surface modification in poly- sapphire slots. This effect was attenuated by an increase in the percentage of surface crystallinity (polycrystalline brackets). No significant difference was noted in the mean frictional resistance value of the test and control groups of the two bracket types with rhodium-coated esthetic wires. On the other hand, polycrystalline brackets in the test and control groups showed higher friction than poly-sapphire brackets, irrespective of laser irradiation.

\section{Authors' contributions}

HG contributed to the design of the study and execution of the procedure, AG designed the study and revised the final manuscript, $\mathrm{SH}$ assisted in laboratory setting and preparation of the article, NC contributed to the determination of lasers settings and collection of the data, and MAK collected the data, analyzed the results, and wrote the article.

\section{Ethical Considerations}

This study was approved by the ethics committee of Tehran University of Medical Sciences. Ethics code: IR.TUMS.DENTISTRY.REC.1397.109.

\section{Conflict of Interests}

The authors declare that they have no conflict of interest.

\section{Funding}

Not applicable.

\section{Acknowledgments}

We would like to acknowledge the outstanding contribution of Dr. Mojdeh Kalantar Motamedi for editing the English manuscript and Dr. Mohammad Javad KharaziFrad for statistical consultation.

\section{References}

1. Bolas-Colvee B, Tarazona B, Paredes-Gallardo V, Arias-De Luxan S. Relationship between perception of smile esthetics and orthodontic treatment in Spanish patients. PloS One. 2018;13(8):e0201102. doi: 10.1371/journal.pone.0201102

2. Singh DP. Esthetic archwires in orthodontics-A review. J Oral Hyg Health. 2016;4(194):2332-0702. doi: 10.4172/2332-0702.1000194

3. AlSubaie M, Talic N, Khawatmi S, Alobeid A, Bourauel C, El-Bialy T. Study of force loss due to friction comparing two ceramic brackets during sliding tooth movement. J Orofac Orthop. 2016;77(5):334-40. doi: 10.1007/s00056016-0038-0.

4. Vinay K, Venkatesh MJ, Nayak RS, Pasha A, Rajesh M, Kumar P. A comparative study to evaluate the effects of ligation methods on friction in sliding mechanics using 0.022 " slot brackets in dry state: an in-vitro study. J Int Oral Health. 2014 Apr;6(2):76.

5. Stasinopoulos D, Papageorgiou SN, Kirsch F, Daratsianos $\mathrm{N}$, Jäger A, Bourauel C. Failure patterns of different bracket systems and their influence on treatment duration: A retrospective cohort study. Angle Orthod. 2018;88(3):338- 
47. doi: 10.2319/081817-559.1

6. Cacciafesta V, Sfondrini MF, Scribante A, Klersy C, Auricchio F. Evaluation of friction of conventional and metal-insert ceramic brackets in various bracket-archwire combinations. Am J Orthod Dentofacial Orthop. 2003; 124(4):403-9. doi: 10.1016/S0889-5406(03)00501-8

7. Oshida Y, Sachdeva RC, Miyazaki S. Microanalytical characterization and surface modification of TiNi orthodontic archwires. Biomed Mater Eng. 1992;2(2):5169.

8. Behroozian A, Kachoei M, Khatamian M, Divband B. The effect of $\mathrm{ZnO}$ nanoparticle coating on the frictional resistance between orthodontic wires and ceramic brackets. J Dent Res Dent Clin Dent Prospects. 2016;10(2):106. doi: 10.15171/joddd.2016.017

9. Dridi A, Bensalah W, Mezlini S, Tobji S, Zidi M. Influence of bio-lubricants on the orthodontic friction. J Mech Behav Biomed Mater. 2016;60:1-7. doi: 10.1016/j. jmbbm.2015.12.026

10. Mirhashemi A, Sharifi N, Moharrami M, Chiniforush N. Evaluation of different types of lasers in surface conditioning of porcelains: a review article. J Lasers Med Sci. 2017;8(3):101- doi: 10.15171/jlms.2017.19.

11. Abdallah RM, Hammouda IM, Kamal M, Abouelatta OB, El-Salamd AA. Evaluation of hardness, surface morphology and structure of laser irradiated ceramics. J Ovonic Res. 2010;6(5):227-38.

12. Kara HB, Dilber E, Koc O, Ozturk AN, Bulbul M. Effect of different surface treatments on roughness of IPS Empress 2 ceramic. Lasers Med Sci. 2012;27(2):267-72. doi: 10.1007/ s10103-010-0860-3

13. Dilber E, Yavuz T, Kara HB, Ozturk AN. Comparison of the effects of surface treatments on roughness of two ceramic systems. Photomed Laser Surg. 2012;30(6):308-14. doi: 10.1089/pho.2011.3153

14. Martins FV, Mattos CT, Cordeiro WJB, Fonseca EM. Evaluation of zirconia surface roughness after aluminum oxide airborne-particle abrasion and the erbium-YAG, neodymium-doped YAG, or CO2 lasers: A systematic review and meta-analysis. J Prosthet Dent. 2019;121(6):895903.e2. doi: 10.1016/j.prosdent.2018.07.001

15. Stubinger S, Homann F, Etter C, Miskiewicz M, Wieland M, Sader R. Effect of Er:YAG, $\mathrm{CO}(2)$ and diode laser irradiation on surface properties of zirconia endosseous dental implants. Lasers Surg Med. 2008;40(3):223-8. doi: 10.1002/lsm.20614

16. Hosseinzadeh Nik T, Hooshmand T, Farhadifard H. Effect of different types of toothpaste on the frictional resistance between orthodontic stainless steel brackets and wires. J Dent(Tehran). 2017;14(5):275-81.

17. Hosseinzadeh Nik T, Hooshmand T, Farazdaghi $H$, Mehrabi A, Razavi ES. Effect of chlorhexidine-containing prophylactic agent on the surface characterization and frictional resistance between orthodontic brackets and archwires: an in vitro study. Prog Orthod. 2013;14:48. doi: 10.1186/2196-1042-14-48

18. Krimm S, Tobolsky AV. Quantitative x-ray studies of order in amorphous and crystalline polymers. Quantitative $\mathrm{x}$-ray determination of crystallinity in polyethylene. J Polym Sci. 1951;7(1):57-76. doi: 10.1002/pol.1951.120070105

19. Pasha A, Vishwakarma S, Narayan A, Vinay K, Shetty SV, Roy PP. Comparison of frictional forces generated by a new ceramic bracket with the conventional brackets using unconventional and conventional ligation system and the self-ligating brackets: an in vitro study. J Int Oral Health. 2015;7(9):108-13

20. Tanne K, Matsubara S, Hotei Y, Sakuda M, Yoshida M. Frictional forces and surface topography of a new ceramic bracket. Am J Orthod Dentofacial Orthop. 1994;106(3):2738. doi: 10.1016/S0889-5406(94)70047-8

21. Bajraktarova-Valjakova E, Korunoska-Stevkovska V, Kapusevska B, Gigovski N, Bajraktarova-Misevska C, Grozdanov A. Contemporary dental ceramic materials, a review: chemical composition, physical and mechanical properties, indications for use. Open Access Maced J Med Sci. 2018;6(9):1742. doi: 10.3889/oamjms.2018.378.

22. Arash V, Rabiee M, Rakhshan V, Khorasani S, Sobouti F. In vitro evaluation of frictional forces of two ceramic orthodontic brackets versus a stainless steel bracket in combination with two types of archwires. J Orthod Sci. 2015;4(2):42-6. doi: 10.4103/2278-0203.156028

23. Feldon PJ, Murray PE, Burch JG, Meister M, Freedman MA. Diode laser debonding of ceramic brackets. Am J Orthod Dentofacial Orthop. 2010;138(4):458-62. doi: 10.1016/j.ajodo.2008.11.028.

24. Ivanov PI. Investigation of diode laser debonding of ceramic orthodontic brackets [dissertation]. Nova Southeastern University; 2012. Available from: https://nsuworks.nova. edu/hpd_cdm_stuetd/52/

25. Kusy RP, Whitley JQ. Effects of surface roughness on the coefficients of friction in model orthodontic systems. J biomech 1990;23(9):913-25. doi: 10.1016/00219290(90)90356-8

26. Kusy RP, Whitley JQ. Coefficients of friction for arch wires in stainless steel and polycrystalline alumina bracket slots. I. The dry state. Am J Orthod Dentofacial Orthop. 1990;98(4):300-12. doi: 10.1016/S0889-5406(05)81487-8

27. Harimkar SP, Dahotre NB. Crystallographic and morphological textures in laser surface modified alumina ceramic. J Appl Phys. 2006;100(2):024901. doi: $10.1063 / 1.2214365$

28. Lee S, Gahr KHZ. Surface treatments of Al2O3-ceramics by CO2-lasers. Mat.wiss U. Werksttech. 1992;23(4):117-23. doi: 10.1002/mawe.19920230406

29. Rabiee SM, Eftekhari SZ, Arash V, Amozegar N, Fathi A, Tavanafar S, et al. Effect of CO2 laser power intensity on the surface morphology and friction behavior of alumina ceramic brackets. Microsc Res Tech. 2017;80(8):923-9. doi: $10.1002 /$ jemt. 22883

30. Arash V, Javanmard S, Eftekhari Z, Rahmati-Kamel M, Bahadoram M. Evaluation of Static Friction of Polycrystalline Ceramic Brackets after Conditioning with Different Powers of Er:YAG Laser. Int J Dent. 2015;2015:749616. doi: 10.1155/2015/749616 